\section{Commentary: Should we start spreading the news? Prognostic influence of spread through air spaces in early-stage lung adenocarcinoma}

\author{
Jules Lin, MD
}

Jung and colleagues ${ }^{1}$ report that spread through air spaces (STAS) is an independent prognostic factor associated with risk of recurrence in patients with early-stage $\mathrm{T} 1 \mathrm{~b}$ and T1c N0 M0 tumors undergoing lobectomy with a risk similar to T2a N0 M0 adenocarcinomas. Routine adjuvant chemotherapy is not currently recommended because randomized studies have not shown a clear benefit. ${ }^{2}$ However, even early-stage lung cancers have a significant risk of recurrence, and identifying risk factors for recurrence is essential to improving survival in these patients.

The concept of STAS was introduced in the 2015 World Health Organization classification for lung cancer. In the past, STAS was dismissed as artifacts from contamination during processing and was often overlooked. One potential concern is that this study was conducted from 2011 to 2016 when STAS may not have been routinely identified. However, the authors state that their pathologist has been reporting detached tumor cells as aerogenous spread since 2008 .

Kadota and colleagues ${ }^{3}$ found that STAS was associated with recurrence after sublobar resection but not after lobectomy in contrast to the current study where the risk of recurrence was higher despite lobectomy. Jung and colleagues ${ }^{1}$ suggest that this may be due to the smaller tumors $(<2 \mathrm{~cm})$ in the study by Kadota and colleagues. ${ }^{3}$ Dai and colleagues ${ }^{4}$ found that the presence of STAS did not affect recurrence in tumors $<2 \mathrm{~cm}$ (T1a and $\mathrm{T} 1 \mathrm{~b})$ but was

From the Section of Thoracic Surgery, Department of Surgery, University of Michigan Medical Center, Ann Arbor, Mich.

Disclosures: Dr Lin has received clinical trial funding from Genentech.

The Journal policy requires editors and reviewers to disclose conflicts of interest and to decline handling or reviewing manuscripts for which they may have a conflict of interest. The editors and reviewers of this article have no conflicts of interest.

Received for publication Oct 17, 2020; revisions received Oct 17, 2020; accepted for publication Oct 20, 2020; available ahead of print Oct 27, 2020.

Address for reprints: Jules Lin, MD, Section of Thoracic Surgery, Department of Surgery, University of Michigan Medical Center, 1500 E Medical Center Dr, 2120TC/

5344, Ann Arbor, MI 48109-5344 (E-mail: juleslin@umich.edu).

J Thorac Cardiovasc Surg 2022;163:286-7

$0022-5223 / \$ 36.00$

Copyright (c) 2020 by The American Association for Thoracic Surgery

https://doi.org/10.1016/j.jtcvs.2020.10.075

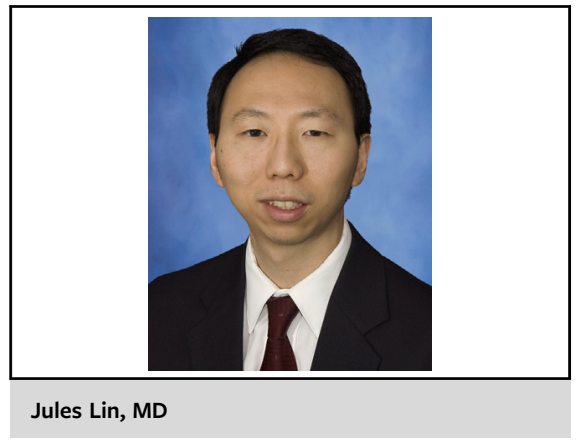

CENTRAL MESSAGE

Spread through air spaces was associated with a higher risk of recurrence with early-stage T1b and T1c lung cancer; further studies are needed to determine how this should change clinical practice.

associated with recurrence in tumors 2 to $3 \mathrm{~cm}$ in size (T1c). However, the extent of resection was not included in the model. Jung and colleagues ${ }^{1}$ evaluated tumors according to $\mathrm{T}$ stage, grouping $\mathrm{T} 1 \mathrm{~b}$ and $\mathrm{T} 1 \mathrm{c}$ together, and did not evaluate T1a tumors because the baseline prevalence of STAS $(6.3 \%)$ was low.

Morimoto and colleagues ${ }^{5}$ found an additive prognostic value of STAS with certain histologic subtypes and suggested upstaging the T stage when a micropapillary component is present with STAS. The current authors found excess risk when analyzing interactions between histologic grade and STAS with a micropapillary pattern. Uruga and colleagues also reported a significant association between increasing amounts of STAS and shorter recurrence-free survival. ${ }^{6}$ Jung and colleagues ${ }^{1}$ did not specifically evaluate the association of the extent of STAS with recurrence.

Shioni and colleagues ${ }^{7}$ found that STAS was an independent prognostic factor for overall and recurrence-free survival in adenocarcinomas $<3 \mathrm{~cm}$. Jung and colleagues ${ }^{1}$ do not specifically evaluate overall survival, but their comments indicate that the association between STAS and overall survival did not reach statistical significance possibly due to confounding factors such as emphysema or changes in the treatment of recurrence over time.

The current study builds on previous publications and continues to spread the news on the prognostic influence of STAS on the risk of recurrence in $\mathrm{T} 1 \mathrm{~b}$ and $\mathrm{T} 1 \mathrm{c}$ tumors even after lobectomy. However, it remains unclear how this news should 
change current clinical practice and whether the presence of STAS should lead to increased surveillance imaging. There is no current role for adjuvant chemotherapy in the treatment of $\mathrm{T} 1 \mathrm{~b}$ or T1c tumors, although these results support further investigation in this area.

\section{References}

1. Jung W, Chung J-H, Yum S, Kim K, Lee CT, Jheon S, et al. The differential prognostic impact of spread through air spaces in early-stage lung adenocarcinoma after lobectomy according to the pT descriptor. $J$ Thorac Cardiovasc Surg. 2022;163:277-84.e1.

2. Pignon JP, Tribodet H, Scagliotti GV, Douillard JY, Shepherd FA, Stephens RJ, et al. Lung adjuvant cisplatin evaluation: a pooled analysis by the LACE Collaborative Group. J Clin Oncol. 2008;26:3552-9.
3. Kadota K, Nitadori JI, Sima CS, Ujiie H, Rizk NP, Jones DR, et al. Tumor spread through air spaces is an important pattern of invasion and impacts the frequency and location of recurrences after limited resection for small stage I lung adenocarcinomas. J Thorac Oncol. 2015;10:806-14.

4. Dai C, Xie H, Su H, She Y, Zhu E, Fan Z, et al. Tumor spread through air spaces affects the recurrence and overall survival in patients with lung adenocarcinoma $>2$ to $3 \mathrm{~cm}$. J Thorac Oncol. 2017;12:1052-60.

5. Morimoto J, Nakajima T, Suzuki H, Nagato K, Iwata T, Yoshida S, et al. Impact of free tumor clusters on prognosis after resection of pulmonary adenocarcinoma. $J$ Thorac Cardiovasc Surg. 2016;152:64-72.e1.

6. Uruga H, Fujii T, Fujimori S, Kohno T, Kishi K. Semiquantitative assessment of tumor spread through air spaces (STAS) in early-stage lung adenocarcinomas. $J$ Thorac Oncol. 2017;12:1046-51.

7. Shiono S, Yanagawa N. Spread through air spaces is a predictive factor of recurrence and a prognostic factor in stage I lung adenocarcinoma. Interact Cardiovasc Thorac Surg. 2016;23:567-72.
See Article page 277

\section{Commentary: STAS is here to STAY}

\author{
Elizabeth A. David, MD, MAS
}

Non-small cell lung cancer (NSCLC) survival is slowly improving as multimodality therapies improve in efficacy for those patients diagnosed with advanced-stage disease. Lung cancer screening, although still drastically underused, is helping to identify more patients with early-stage NSCLC who would potentially be treated with lobectomy. However, recurrence and survival rates after lobectomy have been relatively stagnant over the last 10 years for these patients for reasons that have been poorly understood. Some are now starting to speculate that spread through air spaces (STAS) may be a contributing factor for the previously unexplained recurrence and survival statistics. ${ }^{1,2}$

In this issue of the Journal, Jun and colleagues ${ }^{3}$ analyzed 506 patients who underwent lobectomy for pT1b, pT1c, and pT2a adenocarcinomas according to STAS $+/$ - . For the patients with smaller tumors (pT1b and pT1c),

\footnotetext{
From the Division of Thoracic Surgery, Department of Surgery, Keck School of Medicine, The University of Southern California, Los Angeles, Calif.

Disclosures: The author reported no conflicts of interest.

The Journal policy requires editors and reviewers to disclose conflicts of interest and to decline handling or reviewing manuscripts for which they may have a conflict of interest. The editors and reviewers of this article have no conflicts of interest.

Received for publication Oct 5, 2020; revisions received Oct 5, 2020; accepted for publication Oct 6, 2020; available ahead of print Oct 13, 2020.

Address for reprints: Elizabeth A. David, MD, MAS, Keck School of Medicine, The University of Southern California, 1510 San Pablo St, Suite 514, Los Angeles, CA 90033 (E-mail: elizabeth.david@med.usc.edu).

J Thorac Cardiovasc Surg 2022;163:287-8

$0022-5223 / \$ 36.00$

Copyright (c) 2020 by The American Association for Thoracic Surgery

https://doi.org/10.1016/j.jtcvs.2020.10.022
}

Check for updates

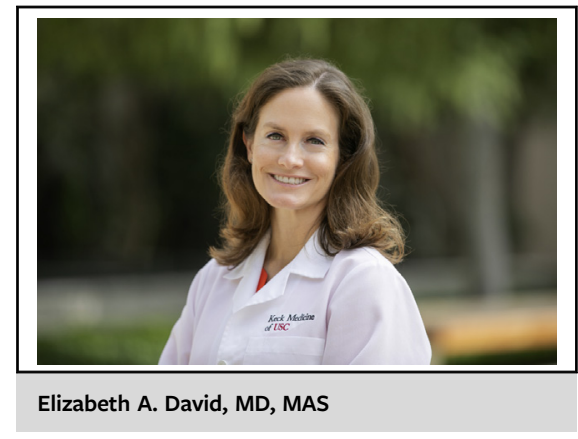

CENTRAL MESSAGE

Assessment of STAS is critical for adequate pathologic staging and risk assessment for all patients with lung cancer.

STAS + patients had a 7-fold and almost 3-fold increased risk of recurrence when compared with STAS- patients. Kaplan-Meier analysis also revealed that pT1b and pT1c STAS + patients had similar survival to pT2a when controlling for smoking status, coronary artery disease, carotid endarterectomy, maximum standardized uptake value, pT, histologic grade, lymphatic invasion, and vascular invasion. The authors conclude that the presence of STAS in pT1b and pT1c N0 adenocarcinomas is associated with similar risk of recurrence as pT2aNOM0 and could be a contributing factor to lower overall survival rates than would be ideally seen for patients with early-stage NSCLC. 